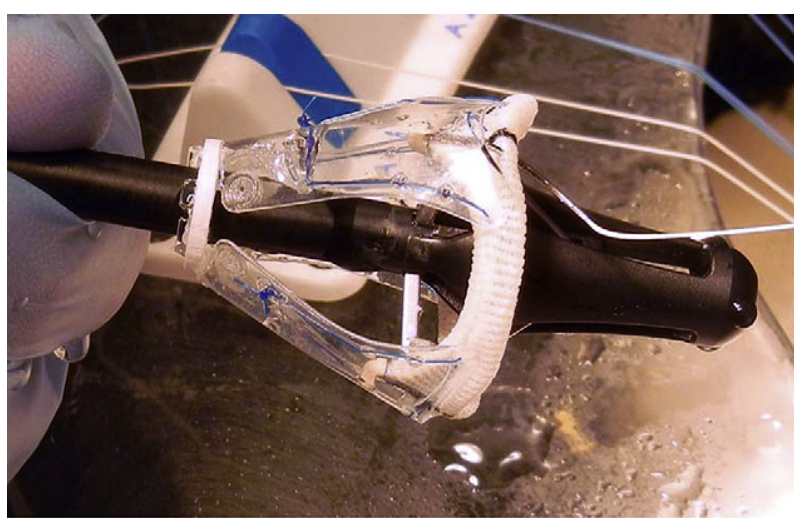

FIGURE 2. The valve base includes 3 clear, pliable shields that cover the hooks and prevent the sutures from tangling during insertion. These shields also act as soft tissue retractors to facilitate greater exposure and visualization during attachment of the leaflet set.

$\mathrm{mm} \mathrm{Hg}$, and $2.0 \mathrm{~mm} \mathrm{Hg}$. Effective orifice areas at that time were $1.35 \mathrm{~cm}^{2}, 1.74 \mathrm{~cm}^{2}$, and $1.35 \mathrm{~cm}^{2}$. At 90 days of follow-up, all 3 patients were symptom free.

\section{DISCUSSION}

One other report has described an easy-to-insert valve with separate components for insertion and removal. ${ }^{2}$ In our 3-patient cohort, the valve was easy to insert, and the shields protecting the stent posts facilitated suture tying. The valve's leaflets did not obstruct inspection and placement of additional sutures. Overall valve performance was excellent.

Safety and durability should be assessed in a larger series of patients. Valve replacement through a transapical approach is currently being investigated, and a working engineering model shows that a transapical approach and leaflet set exchange may be possible.

\section{References}

1. Svensson LG, Blackstone EH, Cosgrove DM 3rd. Surgical options in young adults with aortic valve disease. Curr Probl Cardiol. 2003;28:417-80.

2. Fernandez J, Gonzalez-Lavin L, Maranhao V, Yang SS. A new bioprosthesis for aortic and mitral valve replacement: preliminary evaluation of the Tascon valve. Tex Heart Inst J. 1987;14:31-8.

\title{
Giant vein graft pseudoaneurysm with pulmonary hemorrhage
}

\author{
Zain Khalpey, MD, PhD, MRCS, ${ }^{a}$ Edo Bedzra, MS, ${ }^{\mathrm{b}}$ Michael H. Stella, MD, ${ }^{\mathrm{c}}$ and Patrick O. Myers, MD, ${ }^{\mathrm{a}}$ \\ Boston, Mass
}

Saphenous vein graft (SVG) aneurysms, especially giant ones with severe dilatation, are rare and present with nonspecific symptoms. They occur about 1 decade after surgery and can be life-threatening, with an in-hospital mortality of $15.7 \% .^{1}$ Covered stents have been increasingly used for aneurysm treatment instead of classic surgical excision. ${ }^{2}$ The success of the intervention is time dependent. We report a death from multisystem failure after delayed SVG aneurysm exclusion using covered stent grafts.

\footnotetext{
From the Divisions of Cardiac Surgery ${ }^{\mathrm{a}}$ and Radiology, ${ }^{\mathrm{c}}$ Brigham and Women's Hospital, Harvard Medical School, Boston, Mass; and Harvard Medical School, ${ }^{\mathrm{b}}$ Boston, Mass.

Disclosures: Authors have nothing to disclose with regard to commercial support. Received for publication March 13, 2012; revisions received April 10, 2012; accepted for publication May 7, 2012; available ahead of print June 4, 2012.

Address for reprints: Patrick O. Myers, MD, Division of Cardiac Surgery, Brigham and Women's Hospital, Harvard Medical School, 75 Francis St, Boston, MA 02115 (E-mail: pmyers1@ partners.org).

J Thorac Cardiovasc Surg 2012;144:e14-6

0022-5223/\$36.00

Copyright (C) 2012 by The American Association for Thoracic Surgery

http://dx.doi.org/10.1016/j.jtcvs.2012.05.001
}

\section{CASE REPORT}

An 83-year-old man, who had previously undergone coronary artery bypass grafting 3 decades earlier, underwent a reoperation for a failed circumflex graft, a stenotic posterior descending artery graft, and aortic valve replacement for aortic stenosis. His left anterior descending (LAD) SVG was satisfactory at the time. Three years later, he underwent repeat cardiac catheterization at another institution that showed a $100 \%$ ostial lesion of the LAD and a $70 \%$ lesion proximal to the distal LAD anastomosis. A heparin-coated stent was deployed for a $100 \%$ ostial lesion in the right coronary artery. No particularities were noted regarding the SVG. This was complicated by progressive congestive heart failure, with the ejection fraction reduced to $35 \%$.

The patient developed hemoptysis, was diagnosed with bronchitis and bronchiectasis, and was treated with bronchodilators and antibiotics. He did not have another episode until 4 months later, when he presented with massive hemoptysis. He remained hemodynamically stable during the transfer to our institution and denied shortness of breath or chest pain. Bronchoscopy showed bleeding in the airway, with right-sided bleeding greater 

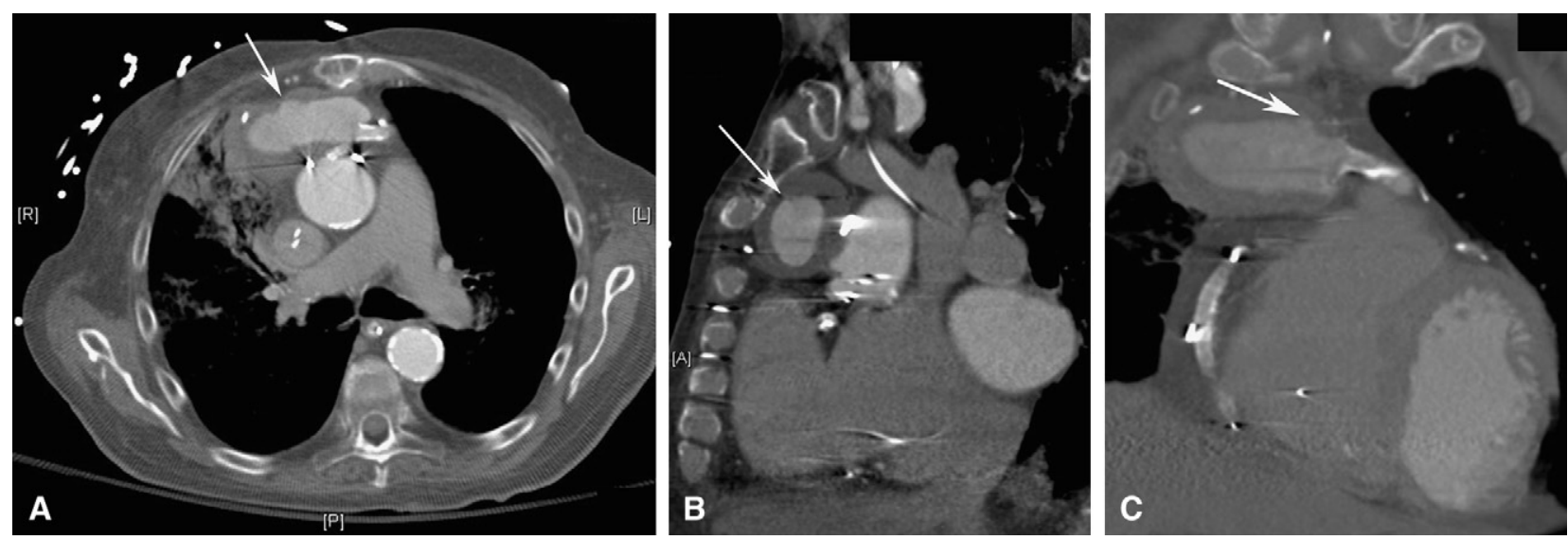

FIGURE 1. Computed tomography angiogram of the saphenous vein graft pseudoaneurysm showing partially thrombosed vein graft to left anterior descending artery (white arrows) measuring $6.8 \times 4.9 \times 3.7 \mathrm{~cm}$. A, Right lung changes consistent with hemorrhage. B, Proximal end of saphenous vein graft. $\mathrm{C}$, Distal end of pseudoaneurysm and graft.

than the left. A computed tomography angiogram showed a $6.8 \times 4.9 \times 3.7-\mathrm{cm}$ partially thrombosed saccular aneurysm arising from the $\mathrm{SVG}$, to the $\mathrm{LAD}, 2 \mathrm{~cm}$ distal to its proximal anastomosis with hemorrhage concerning for an aneurysm leak (Figure 1).

The patient was taken urgently to the catheterization laboratory for percutaneous exclusion of the pseudoaneurysm. A covered stent could not be passed after placement of the guidewires. The patient was thus transferred to the cardiac care unit, pending obtaining larger bore catheters. The patient ultimately underwent successful exclusion of the aneurysm with placement of 3 overlapping covered stents over a $7 \mathrm{~F}$ sheath. No endoleak or extravasation of dye around the stents was noted after the procedure (Figure 2). He experienced a myocardial infarction owing to no-reflow to the LAD. His procedure was complicated by significant blood loss requiring emergent open repair of the left brachial arteriotomy with a bovine pericardial patch. The patient subsequently required increasing hemodynamic support, developed respiratory failure, acute kidney failure requiring venovenous hemodialysis, and ongoing coagulopathy during the next several days. His family decided to withdraw care in accordance with his stated wishes, and the patient died 5 days after presentation.

\section{DISCUSSION}

Severe SVG dilatations are large $(6 \pm 3 \mathrm{~cm})$, occur remotely after surgery, and are life-threatening, with high in-hospital mortality. Hemoptysis and hemothorax are dreaded complications and can quickly result in death. True aneurysms are more common than pseudoaneurysms, which occur in $14 \%$ of patients. ${ }^{1,3}$ These pseudoaneurysms usually occur at proximal anastomosis sites and are thought to occur from tension on the anastomosis or technical issues with suture placement. ${ }^{4}$
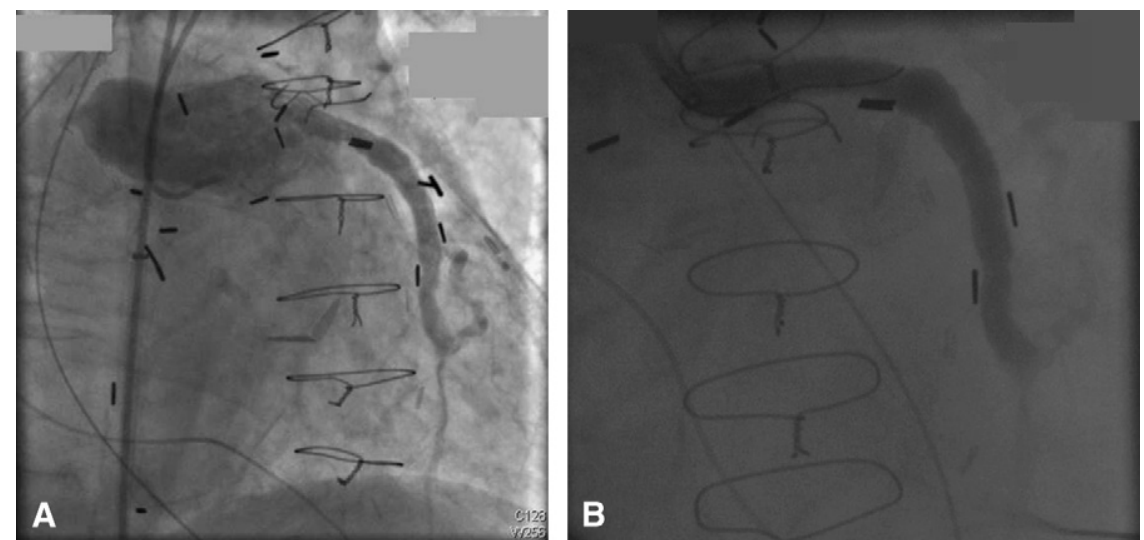

FIGURE 2. Coronary angiograms. A, Preintervention coronary angiogram (right anterior oblique projection) showing proximal saphenous vein graft to left anterior descending artery dilatation. B, Coronary angiogram (right anterior oblique projection) after deployment of 3 covered stents, showing exclusion of saphenous vein graft pseudoaneurysm and limited flow to left anterior descending artery. 
Different treatment options exist for management and are applied according to the anatomy of the aneurysm and flow dynamics in the coronary circulation. Repeat coronary artery bypass grafting with aneurysmal excision is the classic approach. Reports have been published of successful stent placement when continued antegrade flow through the graft is necessary, and coil embolization and vascular plugs have been used in cases in which this is neither necessary nor desired. ${ }^{3,5}$ These can also be particularly useful in patients in whom the risk of bypass surgery is high and because a reoperation, although high risk, does not eliminate the pathologic process of the veins. Endovascular procedures also have risks, however, and our patient illustrates 1 of them. The risk of bleeding, particularly in coagulopathic patients, is real in these procedures.

Ultimately, the outcomes of SVG aneurysm repair depend on acute recognition of the pathologic features from high clinical suspicion, obtaining early diagnostic tests to rule it out, and fast decision making regarding the approach for repair. The stakes are even greater in patients with severe dilatation and/or evidence of aneurysmal leakage.

\section{CONCLUSIONS}

We have described a patient with a giant vein graft aneurysm complicated by a leak and pulmonary hemorrhage. This diagnosis should be suspected in patients remote from coronary artery bypass grafting who present with hemoptysis and can be confirmed by computed tomography angiography. Covered stents can be successfully used to exclude these aneurysms and should be deployed in a timely manner to preclude adverse outcomes.

We would like to thank Dr Frederic Scott Resnic for performing the case.

\section{References}

1. Almanaseer A, Rosman HS, Kazmouz G, Giraldo AA, Martin J. Severe dilatation of saphenous vein grafts: a late complication of coronary surgery in which the diagnosis is suggested by chest x-ray. Cardiology. 2005;104:150-6.

2. Hascoet S, Roncalli J, Galinier M. Voluminous pseudoaneurysm of a saphenous vein graft. Arch Cardiovasc Dis. 2010;103:133-4.

3. Topaz O. Giant aneurysms of saphenous vein grafts: management dilemmas and treatment options. Catheter Cardiovasc Interv. 2006;67:611-6.

4. Kumar A, Santana D, Jenkins LA. Closure of a giant saphenous vein graft aneurysm with embolization coil. Cardiol Res Pract. 2009;2009:748272.

5. Panetta CJ, Schneider W, Boller MA. Percutaneous management of a long saphenous vein graft aneurysm: a case report and review of literature. Cardiol Res Pract. 2009;2009:981292.

\title{
Simultaneous sternal reconstruction and tricuspid valve replacement in a patient with chronic osteomyelitis and absence of tricuspid valve
}

\author{
Byung Kwon Chong, MD, ${ }^{\mathrm{a}}$ Joon Bum Kim, MD, ${ }^{\mathrm{a}}$ and Tae Jin Yun, MD, PhD, ${ }^{\mathrm{b}}$ Seoul, Republic of Korea
}

Chronic sternal osteomyelitis is an uncommon complication of major cardiac surgery and carries significant morbidity and mortality. If this complication is accompanied by severe tricuspid valve (TV) regurgitation and right heart failure, the management is more challenging. We report the successful treatment of such a case by simultaneous TV replacement and sternal reconstruction.

\footnotetext{
From the Department of Thoracic and Cardiovascular Surgery ${ }^{\mathrm{a}}$ and Division of Congenital Cardiac Surgery, ${ }^{\text {b }}$ Asan Medical Center, University of Ulsan College of Medicine, Seoul, Republic of Korea.

Disclosures: Authors have nothing to disclose with regard to commercial support.

Received for publication March 27, 2012; accepted for publication May 7, 2012; available ahead of print June 11, 2012.

Address for reprints: Joon Bum Kim, MD, Department of Thoracic and Cardiovascular Surgery, Asan Medical Center, 88, Olympic-Ro 43-Gil, Songpa-Gu, Seoul 138-736, Republic of Korea (E-mail: jbkim1975@amc.seoul.kr).

J Thorac Cardiovasc Surg 2012;144:e16-8

0022-5223/\$36.00

Copyright (C) 2012 by The American Association for Thoracic Surgery

http://dx.doi.org/10.1016/j.jtcvs.2012.05.006
}

\section{CASE REPORT}

A 65-year-old woman with type 2 diabetes mellitus and hypertension was admitted because of painful swelling of the anterior chest wall. She had a history of ventricular septal defect closure 13 years previously. Nine days postoperatively, sternal wound revision was done because of a deep sternal infection. She was readmitted 7 months later with endocarditis of the TV caused by methicillin-resistant Staphylococcus aureus and underwent tricuspid valvectomy through a right thoracotomy approach. During the ensuing 13 years, she experienced 5 episodes of sternal infection, which were treated by soft tissue debridement and vacuum-assisted closure.

At the present evaluation, she complained of dyspnea equivalent to New York Heart Association functional class III with prominent neck vein engorgement. Her temperature was $38.1^{\circ} \mathrm{C}$. The sternal wound was disrupted to a depth of 3 to $4 \mathrm{~cm}$ with a purulent discharge. The laboratory findings included a leukocyte count of $16,000 / \mathrm{mm}^{3}(94.6 \%$ polymorphonuclear cells) and C-reactive protein of 21.13 